\title{
Novas perspectivas para a indeterminação do sujeito no PB: ultrapassando os limites das gramáticas tradicionais
}

Elizete Maria de SOUZA *

Resumo: O presente estudo investiga um dos recursos de indeterminação do sujeito: o uso da terceira pessoa, masculino plural, em suas realizações plena e nula. O interesse principal é discutir porque a 'Gramática Tradicional' não considera novas formas de indeterminação, tal como o pronome 'eles', como um recurso de indeterminação no $\mathrm{PB}$.

Palavras-chave: Pronome 'eles'; Indeterminação do sujeito; Gramática tradicional.

Abstract: The present study investigates one of the resources of the subject indetermination: the use of the third person, masculine plural, in its full and zero realizations. The main interest is to discuss why 'the traditional grammar' does not consider new forms of indetermination, like 'they' pronoun, as a resource of indetermination in Brazilian Portuguese.

Keywords: 'They' pronoun; Subject indetermination; 'The traditional grammar'.

* Doutoranda em Estudos Linguísticos pela Universidade Federal de Minas Gerais. Professora da R.M.E. de Belo Horizonte. Contato: leesouza@yahoo.com.br. 


\section{Introdução}

O objetivo do presente estudo é investigar o recurso de indeterminar o sujeito através do pronome 'eles' na fala de belorizontinos a fim de discutir o fenômeno dentro de um quadro mais geral de indeterminação, levando em consideração as descrições das gramáticas tradicionais (GTs).

(1) Tô num momento que eu vou te falar, é aquela brincadêra que eles fazem. O Brasil só tem duas saídas: Galeão e Cumbica.

(2) Ninguém tem onde morá, então eles vão pros bairros mais próximos.

(3) Eles servem uns crepes ótimos, aqui. ${ }^{1}$

Conforme mostram os dados acima, o uso do pronome 'eles' tem sido utilizado como um recurso natural para indeterminar o sujeito no português brasileiro atual (doravante PB), o que pode ser constatado através das seguintes paráfrases: a sentença (1) teria como paráfrase: "É aquela brincadeira que fazem", em que o uso da $3^{a}$ pessoa do plural indicaria o desconhecimento do agente, tal como "Bateram na porta". Em (2), 'eles' tem como referente 'todos' os membros de uma classe - um genérico. A sentença (3) teria como paráfrase "Servem-se crepes!"

As Gramáticas Tradicionais admitem cinco recursos de indeterminação do sujeito no PB, a saber: (i) uso do -se e verbo ativo na $3^{a}$ pessoa do singular; (ii) verbo na $3^{a}$ pessoa do plural, sem sujeito gramatical expresso; (iii) deixando-se o verbo no infinitivo impessoal; (iv) construção com pronome indefinido: ninguém, alguém, tudo; (v) uso de a gente e verbo na $3^{\mathrm{a}}$ pessoa do

\footnotetext{
${ }^{1}$ Os dados (1-4) fazem parte do corpus 'Fala Belorizontina', organizado pela prof. ${ }^{a}$ Dr. ${ }^{a}$ Jânia Ramos e agora por mim ampliado para a composição da amostra utilizada nesse estudo.
} 
singular. Um sexto recurso - uso do pronome 'eles' + verbo na $3^{\text {a }}$ pessoa do plural, tal como em (1-3) acima, é geralmente omitido.

É nosso objetivo, portanto, contrapor o uso da forma plena 'eles' com o uso da forma nula de $3^{\text {a }}$ Pessoa, masculino plural, a fim de investigar o uso do pronome 'eles' em contextos de indeterminação.

(4) Aí quando eu saí, era um cara que tava falano. Aí nós morremos de rir. Tinha um cara e $\varnothing$ apelidaram o Alexandre de Dinan. Num sei de onde que eles tiraram esse apelido.

Vejam-se aqui duas realizações de sujeito indeterminado, mas apenas na segunda a forma nula cede lugar à forma plena.Uma das hipóteses assumidas no decorrer desse estudo é que o pronome 'eles', ao lado de outras formas pronominais tais como: eu, você, nós, a gente, por exemplo, é usado como um recurso natural de indeterminação do sujeito no português, apresentando-se como a forma preferida pelos falantes belorizontinos para indeterminar o sujeito se comparada ao uso da forma vazia de $3^{a}$ pessoa, plural, o que seria um novo passo no processo de tendência de preenchimento do sujeito no português brasileiro.

\section{Conceituações de sujeito indeterminado}

A ocorrência de sujeito indeterminado normalmente está associada à não especificação do agente da ação verbal (cf. BECHARA, 1988, p. 200). Ali (1966, p. 122), por exemplo, considera o sujeito indeterminado "o que indica um ente humano que não podemos ou não queremos especificar"; Melo (1978, p. 122) diz que "o que torna o sujeito indeterminado é a intenção do falante, que não sabe ou não quer precisar, apontar o agente, que se supõe ser sempre um ser humano"; Rocha (1984, p. 34) define o sujeito indeterminado quando "o falante não pode, ou não quer, ou não deve envolver-se ou comprometer-se na sua expressão"; Cunha e Cintra (1985, p. 125), "por se desconhecer quem executa a ação, ou por não haver interesse no seu conhecimento". 
A partir do critério semântico, as gramáticas normativas prescrevem, como já dissemos no início desse trabalho, cinco recursos de indeterminação, sem fazer referência à possibilidade de outros recursos utilizados pelos falantes. O que os gramáticos geralmente fazem é explicitar o fenômeno através de exemplos, sem estabelecer um conceito que dê conta de englobar um número maior de possibilidades de se indeterminar o sujeito no PB. Vejamos alguns exemplos arrolados por alguns gramáticos:

(5) Precisa-se de faxineira. (ROCHA LIMA, 1968, p. 226)

(6) Na rua olhavam-no com admiração (CEGALLA, 1994, p. 296)

(7a) Ninguém chegou.

(7b) Alguém bateu à porta.

(7c) Tudo nos interessa. (ROCHA LIMA, 1968, p. 227)

(8) A gente nunca sabe. (CUESTA Y MENDES, 1961, p. 352)

9) É penoso carregar aquilo sozinho. (CEGALLA, 1994, p. 296)

Há, porém, algumas questões que se colocam diante destes dados. Uma vez que observamos em nossa língua um conjunto de formas pronominais indeterminadoras do sujeito (cf. Duarte, 1995; Micheletti e Franchetti, 1996; Omena, 1999; entre outros) os estudos têm mostrado que o PB admite inúmeras formas que ultrapassam o conjunto descrito nas GTs.

Com base nisso, não seria oportuna a descrição de novas formas de indeterminação do sujeito pela GT? E, de fato, não estaria o pronome 'eles' indeterminador do sujeito concorrendo com a forma de $3^{a}$ pessoa no plural, sem sujeito gramatical expresso, recurso tradicionalmente prescrito pelos gramáticos?

Diante dessas questões, passamos, então, às observações de alguns linguistas sobre o uso do 'eles' no fenômeno de indeterminação.

Assumindo uma posição diferente dos gramáticos, os linguistas têm dado bastante atenção ao uso de formas pronominais como estratégias de indeterminação do sujeito em nossa língua. 
Duarte (1995, p. 82) analisa 1.756 dados de sintagmas nominais em posição de sujeito e verifica que 332 dados (19\%) têm referência arbitrária, ou seja, não possuem um referente explícito, i.e., são indeterminados, sendo $65 \%$ representados por pronome pleno - 215 dados, e $35 \%$ por pronome nulo - 117 dados. Desse total, $10 \%$ são preenchidos com o pronome de $3^{a}$ pessoa no masculino plural. Foram identificadas, portanto, 22 ocorrências com o pronome 'eles', conforme nos mostram os dados abaixo: ${ }^{2}$

(10) Quando eles querem, eles fazem.

(11) Quando eles querem, eles acham dinheiro.

(12) O Grajaú eles tão asfaltando, melhorando também.

(13) Aquela rua Teodora da Silva, eles tão recapeando ela também.

(14) A avenida das Américas, eles tão recapeando ela toda, né?

Micheletti e Franchetti (1996), sob a ótica funcionalista, também documentam o uso do pronome de $3^{a}$ pessoa no masculino plural - eles + verbo - para indeterminar o sujeito. De acordo com as autoras, a forma eles não é a forma predominante na indeterminação do sujeito, ela aparece em segundo lugar (23,69\%), ao lado da forma você $(30,89 \%)$. Segundo as autoras, a distribuição acima estaria condicionada à situação de conversação. O caráter de eles se relacionaria com algo fora da situação de conversação, enquanto a forma você parece ter um caráter especial dentro do discurso, dando mais proximidade ao interlocutor. ${ }^{3}$

(15) Eu fui a uma livraria uma vez e perguntei se havia um dicionário [...] fui perguntar se eles tinham aquele mesmo dicionário num tamanho menor.

\footnotetext{
${ }^{2}$ Os dados (10-14) foram tirados de Duarte (1995).

${ }^{3}$ Os dados (15-17) foram tirados de Micheletti e Franchetti (1996).
} 
(16) Se você vai arrumá serviço numa casa assim:: de:: pra trabalha, assim:: fala que é faxineira, ela te dispensa na hora que você fala que mora na favela, ela te dispensa na hora porque eles têm medo porque pra eles quem mora na favela é tudo bandido.

(17) Meu irmão, por exemplo, quando esteve lá falou que isso vira atração turística né e eles iam pra lá.

Corrêa (1998) analisa as realizações plena e reduzida de pronomes pessoais de $3^{\mathrm{a}}$ pessoa, no português falado na cidade de Belo Horizonte, a saber: eles/eis; ela/éa; ele/el. A partir de 1.359 dados coletados em 27 entrevistas com informantes naturais de Belo Horizonte, o autor identifica 161 ocorrências de uso das formas eles/eis como sujeito indeterminado. Ele também observou que a forma eles é usada ainda que o SN antecedente seja masculino ou feminino, singular ou plural. ${ }^{4}$

(18) Eu fui na casa de uns parentes meus, eles é meio assim, eles moram no bairro I.

(19) Porque os professores lá é assim. Cada dia ês explica uma matéria diferente.

(20) O suíço tem pelo menos três línguas e eles vão para fora, para a Inglaterra, para aprender inglês.

(21) Passou uma semana, na outra eles mandaram uma carta pra mim.

(22) E tá chegano o final do ano, eis gosta é de ferrar a gente.

\section{A variação entre as formas nula e plena de $3^{a}$ pessoa, masculino plural, na fala belorizontina}

Em nosso estudo, adotamos os pressupostos teóricometodológicos da sociolinguística laboviana (LABOV, 1972; 1982;

${ }^{4}$ Os dados (18-22) foram tirados de Corrêa (1998). 
1994; 2001) a fim contrapor o uso de \{'eles' + verbo $\}$ e o uso de $\{\varnothing+$ verbo no plural $\}$, buscando ampliar os estudos sobre a indeterminação.

Partindo do pressuposto de que toda língua falada por diferentes comunidades apresenta variações, o que a sociolinguística variacionista busca é mostrar que as variações não são aleatórias; elas ocorrem de forma sistemática via um controle rigoroso de regras. Quando o falante faz uso do pronome 'eles', em sua forma plena, em oposição ao uso da forma vazia, por exemplo, existe um conjunto de fatores que atua no favorecimento à escolha de uma forma em detrimento de outra. Dimensionar esse tipo de covariação é outro dos nossos objetivos neste trabalho.

Utilizamos para isso um corpus de língua falada, constituído de conversas em situações informais, obtidas junto a 36 informantes nascidos em Belo Horizonte e/ou residentes na capital mineira desde a idade inferior a 14-16 anos. A partir de duas amostras década de 90 e década atual -, fizemos um levantamento de 935 dados que foram submetidos ao programa de regras variáveis Goldvarb 2001 (ROBINSON; LAWRENCE; TAGLIAMONTE, 2001), e verificamos num período de 10 anos um percentual de $8 \%$ a mais de uso da forma 'eles' (65\%), com relação ao uso da forma vazia $(57 \%)$, para expressar o sujeito com referência +/- definida. Nessa etapa da pesquisa consideramos todas as realizações do pronome 'eles' com SNs antecedentes [+definidos], [+coletivos], [+genéricos], [+locativos] e [-definidos]. ${ }^{5}$

Com base num estudo de tendência, i.e., comparando dados de dois períodos de tempo - década de 90 e década atual -, foi possível verificar que o uso da forma plena em detrimento da forma vazia se encontra em processo de mudança, apresentando resultados que apontam para uma tendência de maior uso do pronome 'eles',

\footnotetext{
${ }^{5} \mathrm{O}$ detalhamento desses grupos de antecedentes será apresentado na seção 5 .
} 
lexicalmente realizado, o que possivelmente está relacionado com o aumento de preenchimento do sujeito no português brasileiro.

\section{Resultados}

\subsection{A faixa etária dos informantes}

Foram consideradas três faixas etárias: (i) jovens - 15 a 29 anos; (b) adultos - 30 a 49 anos; (c) velhos - 60 a 69 anos. Observou-se em todas as faixas etárias um índice superior de ocorrência da variante plena, conforme mostra o gráfico a seguir.

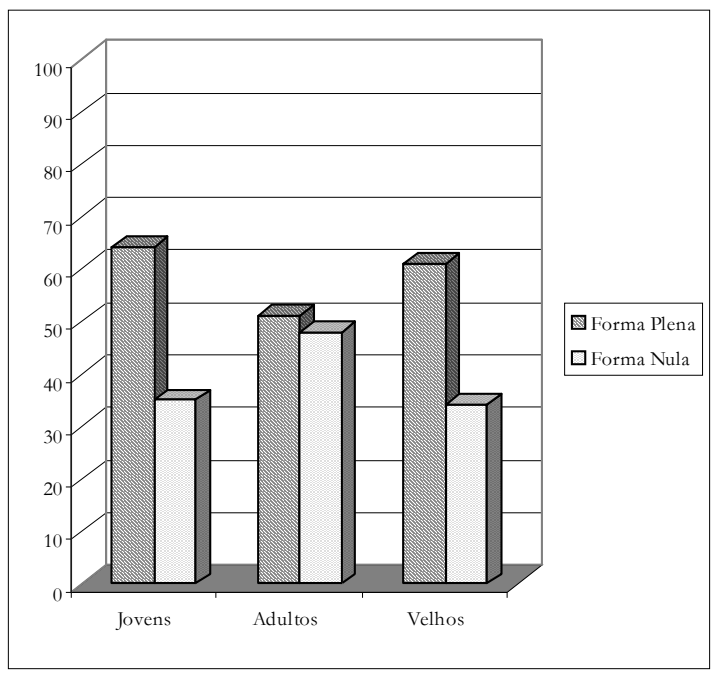

Gráfico 1 - Distribuição das formas nula e plena, conforme a faixa etária dos informantes

Observa-se que na faixa etária de adultos, cujas pessoas geralmente estão inseridas no mercado de trabalho e, por isso mesmo, se mostram mais cuidadosas com a linguagem, o pronome pleno supera o uso da forma vazia, porém com uma diferença 
pouco significativa de apenas 3\%. No caso do nosso estudo em especial, há que se considerar também que estamos utilizando dados de fala de Belo Horizonte que, por ser uma capital, tem um mercado profissional muito competitivo, o que muito provavelmente pode favorecer o uso da variante padrão pelos adultos.

\subsection{O fator gênero do informante}

Considerando o gênero do informante, foi possível verificar que as mulheres apresentam índices superiores de preenchimento. Isso revela que a variante inovadora 'eles' não é estigmatizada pelos falantes. Segundo Labov (2001) e outros, as mulheres são responsáveis por levar adiante formas inovadoras não estigmatizadas.

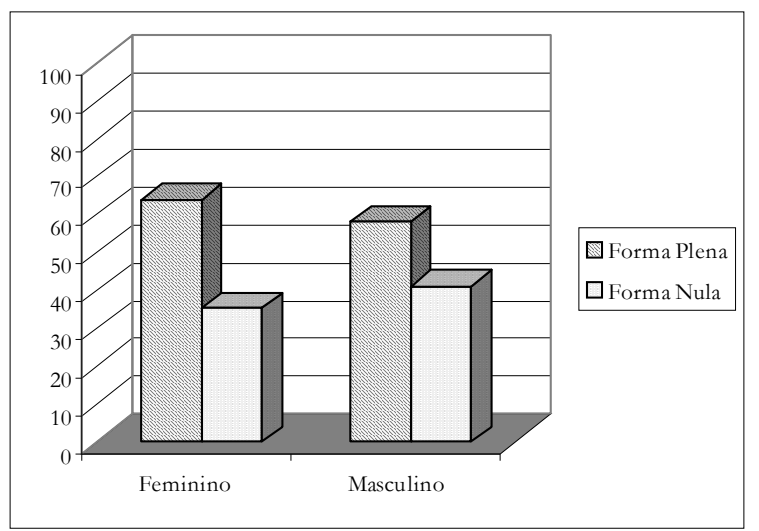

Gráfico 2 - Distribuição das formas nula e plena, conforme o gênero do informante

\subsection{O fator escolaridade}

Nossos informantes foram selecionados de acordo com níveis de escolaridade distintos: ensino superior e não superior. 
Curiosamente, os informantes com nível não superior apresentaram maior percentual de uso do pronome 'eles' pleno. Isso mostra que quanto maior o nível de escolarização mais sensível o informante se mostra em relação ao uso da forma $\varnothing+3^{a}$ pessoa no plural forma tradicionalmente prescrita pelas gramáticas normativas.

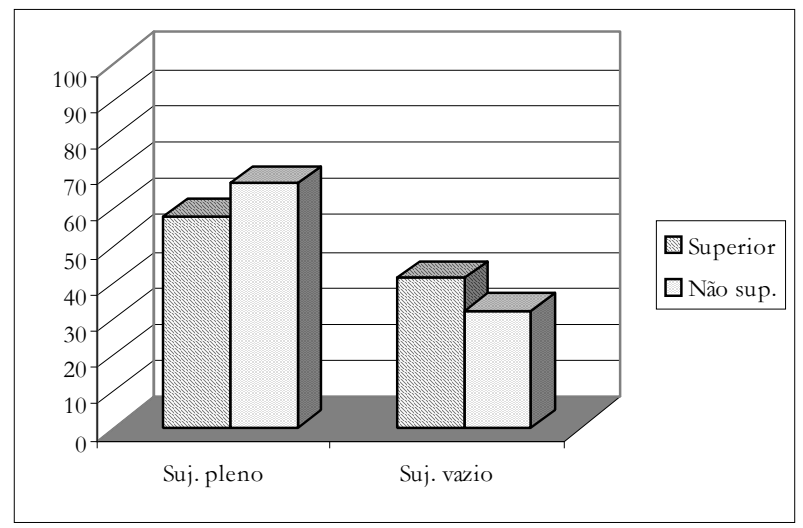

Gráfico 3 - Ocorrência de sujeito pleno e vazio, conforme o nível de escolaridade

Conforme vimos, o pronome 'eles' vem ocupando paulatinamente o espaço da variante nula. Esses resultados mostram que, entre a escolha da forma plena e da forma nula de $3^{a}$ pessoa, masculino plural, a variante inovadora tem ocupado um espaço antes majoritariamente ocupado pela forma nula, o que fortalece a hipótese de que há uma tendência de preenchimento da posição sujeito no português brasileiro. Mas, existe ainda outra questão com relação ao uso do 'eles'. Tal pronome seria usado de forma bipolar apenas, i.e., como sujeito determinado ou sujeito indeterminado, ou haveria etapas que nos permitiriam traçar um percurso do 'eles' numa provável escala de indeterminação do sujeito no português brasileiro atual? $\mathrm{Na}$ tentativa de buscar respostas para estas questões, passemos às próximas seções. 


\section{O percurso do pronome 'eles' na escala de indeterminação}

Quando dizemos que a GT apenas prescreve algumas formas de indeterminação do sujeito sem prever outros recursos possíveis, assim o fazemos para mostrar que a indeterminação através do pronome 'eles' requer um estudo que não se limita a simples identificação do agente da ação verbal para dizer se o sujeito é ora determinado, ora indeterminado, simplesmente. Isso ocorre porque o pronome 'eles' é capaz de retomar vários tipos de $\mathrm{SNs}$ antecedentes que vão determinar os contextos linguísticos de maior ou menor grau de indeterminação, como mostra o gráfico a seguir:

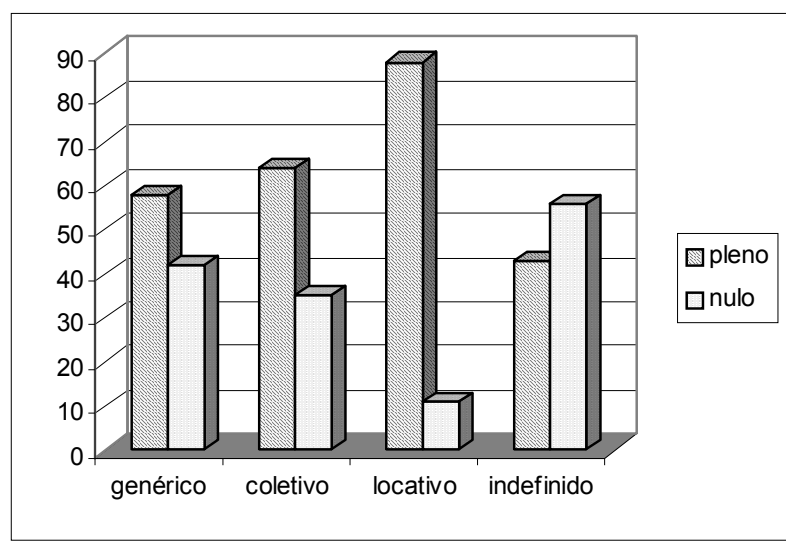

Gráfico 4-Distribuição das formas plena e nula em contextos de indeterminação

Esses resultados mostram que o contexto linguístico que antecede o pronome 'eles' é fundamental para a ocorrência do sujeito indeterminado. Ao retomar diferentes tipos de $\mathrm{SNs}$ antecedentes, o pronome 'eles' apresenta diferentes graus de indeterminação, o que nos permite supor que existe um perfil do avanço da variante plena no percurso de indeterminação, conforme mostra o gráfico 5 : 


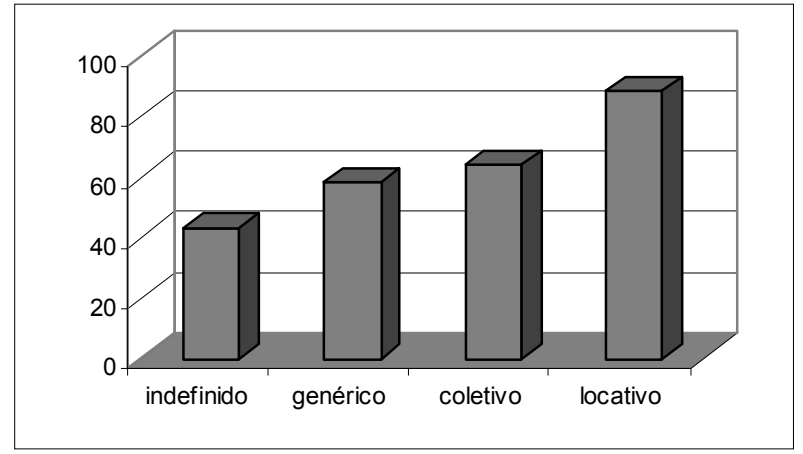

Gráfico 5 - Perfil do avanço da variante plena nos contextos de indeterminação

A partir desse gráfico, identificamos os contextos linguísticos de maior e de menor resistência à ocorrência do 'eles', totalmente indeterminado, i.e., sem nenhum tipo de referência anafórica. $\mathrm{O}$ grupo dos locativos é o que apresenta maior resistência à ocorrência do 'eles' indeterminado, ao lado do grupo dos nomes coletivos e genéricos. Esse perfil do avanço da variante plena mostra que, à medida que o referente vai se tornando menos específico, i.e., menos definido, aumentam-se as chances de ocorrência do 'eles' indeterminado.

\section{Contextos de indeterminação do 'eles'}

Conforme vimos anteriormente, foram identificados quatro contextos linguísticos para a ocorrência do pronome 'eles': locativo $>$ coletivo $>$ genérico $>$ indefinido. A definição de cada um desses contextos, entretanto, não é tarefa fácil, haja vista a semelhança entre alguns deles. Por isso mesmo faz-se necessária a definição de cada um deles, bem como a adoção de critérios que possam auxiliar para melhor definir cada grupo. Vejam-se os dados a seguir: 
(23) Os americanos, eles são muito práticos. (S)

(24) Ainda não tenho candidato porque eles prometem mais num cumpre. (RMT)

(25) O pessoal, eles num vão porque têm medo de tubarão. (DAF)

(26) A gente foi trabalhá num vilarejo bem pobre, lá eles num tinham banheiro. (MCVJ)

(27) Quando Getúlio suicidou, eles falaram que os operários... (JOL)

Em (23) temos um antecedente anafórico [+definido] que determina o sujeito da oração. Nesse caso o pronome 'eles' mantém com seu antecedente uma relação de correferência, sendo clara a especificação do agente da ação verbal. As sentenças (24) e (25), embora permitam a identificação do agente da ação verbal, não podem ser tratadas da mesma forma que a sentença (23), pois o antecedente de ambas não especifica 'o agente', e sim um conjunto de elementos que representa um grupo genérico ou coletivo. Câmara Júnior (1983) esclarece o termo:

Diz-se que uma palavra é genérica (ou que tem um sentido genérico) quando serve para nomear uma classe natural de seres e objetos de cada um dos quais, tomado separadamente, recebe uma denominação particular. Assim a palavra 'peixe' é o genérico de uma classe cujos membros são: o lambari, a traíra, etc. Em português, o artigo definido (o) pode conferir ao $\mathrm{SN}$ que ele constitui com um nome esse valor genérico. Assim o lambari pode ser, por sua vez, um genérico; a categoria natural assim constituída tem por membros 'lambaris' específicos. (CÂMARA JÚNIOR, 1983, p. 302)

Por outro lado, chama-se coletivo "um traço distintivo da categoria de número que indica a representação de um grupo de entidades, isoláveis, consideradas como um todo. Os substantivos coletivos podem ser derivados de substantivos contáveis por meio de afixos específicos, como 'al' em pessoa $\rightarrow$ pessoal" (DUBOIS, 1991, p. 116). 
Para distinguir um nome genérico de um nome coletivo adotamos, ainda, os seguintes critérios:

(a) Os nomes genéricos aceitam ser pluralizados sem causar nenhum problema à sua interpretação como nomes que abrangem um conjunto geral, i.e., genérico. Ex.: o estrangeiro $\rightarrow$ os estrangeiros; o parisiense $\rightarrow$ os parisienses; candidato $\rightarrow$ candidatos.

(b) Os nomes coletivos, por sua vez, não podem ser pluralizados como os genéricos, uma vez que os nomes coletivos são "substantivos que, morfologicamente no singular, indicam pluralidade de seres". (JOTA, 1976). Sendo assim, 'o pessoal' não aceita plural, como acontece com os nomes genéricos. 'Os pessoais', portanto, seria agramatical em nossa língua. O plural de 'o povo', 'o exército', por exemplo, modificaria a interpretação desses substantivos como nomes coletivos. O exército, sendo o coletivo de soldados, passaria a designar no plural o conjunto de vários exércitos; os povos, o conjunto de povos de diferentes nações, e não o coletivo de várias pessoas.

Em (26) observamos um caso bastante curioso. Temos como antecedente para o pronome 'eles' o grupo dos locativos, que, segundo Jota (1976, p. 67), "é o caso que indica o lugar onde se processa a ação verbal". Quando temos 'um vilarejo', 'lá', o pronome 'eles' parece estar numa etapa mais avançada no percurso de indeterminação, caminhando para se tornar totalmente indeterminado. Em (27), o pronome 'eles' carrega o traço [-definido]. Esse traço indefinido, segundo Dubois (1991, p. 337) é interpretado semanticamente pela ausência de toda referência a um SN anterior.

Com base nessas definições, é possível traçar uma escala para o percurso do 'eles' indeterminador do sujeito, mostrando que, entre o sujeito determinado, de um lado, e o sujeito indeterminado, de outro, existem etapas que marcam o processo 
de indeterminação. O sujeito não é simplesmente, ora determinado, ora indeterminado; o que existe são graus diferentes de indeterminação, que podem ser definidos pelo tipo de SN antecedente que ocorre com o pronome 'eles'.

\section{Considerações finais}

Considerando o quadro mais geral de indeterminação do sujeito no português brasileiro, vimos que as gramáticas tradicionais não descrevem todos os recursos de que a língua dispõe. Foi possível mostrar, também, que o uso do pronome 'eles' tem sido um recurso natural para indeterminar o sujeito na fala belorizontina, trazendo evidências de que o uso de 'eles' segue um percurso na escala de indeterminação, que vai do definido ao indefinido, ou seja, determinado/indeterminado, considerando os diferentes graus de indeterminação. Vimos, também, que a indeterminação do sujeito através do pronome 'eles' contribui para o fenômeno de preenchimento do sujeito no $\mathrm{PB}$ atual, uma vez que o falante usa a forma plena em contextos que antes eram tradicionalmente ocupados pela forma vazia de $3^{a}$ pessoa no plural.

Os resultados apresentados mostram, portanto, que, de acordo com os limites estabelecidos pelos gramáticos para a descrição do sistema de indeterminação do sujeito no português, faz-se necessário redimensionar o quadro de indeterminação de forma a incluir novos recursos que se têm mostrado muito produtivos no $\mathrm{PB}$.

\section{Referências}

ALI, Said. Gramática secundária da língua portuguesa. 7. ed. São Paulo: Melhoramentos, 1966.

ALVES, Nilton Antonio. Formas de indeterminação do sujeito. 1998. Dissertação (Mestrado em Letras) - Universidade Federal de Minas Gerais, Belo Horizonte. 
BECHARA, Evanildo. Lições de Português pela análise sintática. 15. ed. Rio de Janeiro: Padrão, 1992.

CÂMARA JUNIOR, Joaquim Mattoso. Estrutura da língua portuguesa. 13. ed. Petrópolis: Vozes, 1983.

CEGALLA, Domingos Paschoal. Novíssima gramática da língua portuguesa. 39. ed. São Paulo: Nacional, 1994.

CORREAA, Lucas Teles. A forma clítica de pronome pessoal no dialeto mineiro: uma variante sociolingüística. 1998. Dissertação (Mestrado em Letras) - Universidade Federal de Minas Gerais, Belo Horizonte.

CUNHA, Celso. Gramática do português contemporâneo. Belo Horizonte: Bernardo Álvares, 1978.

.; CINTRA, Lindley. Nova gramática do português contemporâneo. Rio de Janeiro: Nova Fronteira, 1985.

DUARTE, Maria Eugênia Lamoglia. A perda do princípio "evite pronome" no português brasileiro. 1995. Tese (Doutorado em Estudos da Linguagem) - Universidade Estadual de Campinas, Campinas.

; KATO, Mary A.; BARBOSA, Pilar. Sujeitos indeterminados em PE e PB. In: Congresso Internacional da ABRALIN, 2., Fortaleza, mar. 2001. (Comunicação oral)

DUBOIS et al. Dicionário de lingüística. São Paulo: Cultrix, 1991.

JOTA, Zélio dos Santos. Dicionário de lingüística. 2. ed. Rio de Janeiro: Presença/INL-MEC, 1981.

LABOV, Willian. Principles of Linguistic Change: Social Factors. Oxford: Blackwell, 2001.

Principles of Linguistic Change: Internal factors. Oxford: Blackwell, 1994. 
Sociolinguistic Patterns. Philadelphia: University of Pennsylvania Press, 1972.

MELO, Gladstone Chaves de. Gramática fundamental da língua portuguesa. 3. ed. Rio de Janeiro: Livro Técnico, 1978.

MICHELETTI, Helena; FRANCHET'TI, S. K. A indeterminação do sujeito: um estudo sociolingüístico. Estudos Lingüísticos, v. XXV, p. 629-635, 1996.

MOLLICA, Maria Cecília. Fundamentação Teórica: conceituação e delimitação. In: ; BRAGA, Maria Luiza. Introdução à sociolingüística - o tratamento da variação. São Paulo: Contexto, 2003. p. $9-14$

OMENA, Nelize Pires de. A referência à primeira pessoa do discurso no plural. In: OLIVEIRA E SILVA, Gisele M.; SCHERRE, Maria Marta P. (Orgs.) Padrões sociolingüísticos: análise de fenômenos variáveis do português falado na cidade do Rio de Janeiro. Rio de Janeiro: Tempo Brasileiro, 1996. p. 183-215.

ROCHA, Antônio de Abreu. Gramática e linguagem: curso de português. Belo Horizonte: Vigília, 1984.

ROLLEMBERG, Vera et al. Os pronomes pessoais e a indeterminação do sujeito na norma culta de Salvador. Estudos Lingüísticos e Literários II. Salvador: UFBA, 1991.

SILVA, Giselle Machline de Oliveira e. Coleta de dados. In: MOLLICA, Maria Cecília; BRAGA, Maria Luiza. Introdução à sociolingüística - o tratamento da variação. São Paulo: Contexto, 2003. p. 117-134.

WEINREICH, Uriel; LABOV, Willian; HERZOG, Marvin. Empirical foundations for a theory of language change. In: LEHMANN, Winfred P.; MALKIEL, Yakov. (Eds.) Directions for historical linguistics. Austin: University of Texas Press, 1968. 